\title{
Regional and Total Skeletal Measurements in the Early Postmenopause
}

\author{
John C. Stevenson, Linda M. Banks, Terry J. Spinks, Chris Freemantle, lain Macintyre, \\ Richard Hesp, Geoff Lane, Julie A. Endacott, Malcolm Padwick, and Malcolm I. Whitehead \\ Endocrine Unit and Department of Diagnostic Radiology, Royal Postgraduate Medical School, and Medical Research Council \\ Cyclotron Unit, Hammersmith Hospital, London W12 OHS; Division of Radioisotopes, Clinical Research Centre, \\ Northwick Park Hospital, Harrow HA1 3UJ; and Academic Department of Obstetrics and Gynaecology, \\ King's College School of Medicine and Dentistry, London SE5 8RX, United Kingdom
}

\begin{abstract}
In a cross-sectional study of $\mathbf{7 0}$ early postmenopausal women, regional bone measurements were compared with total body calcium (TBCa). Spinal and forearm trabecular bone were mainly related to age and time since menopause. In contrast, TBCa and forearm integral (cortical and trabecular) and cortical bone were unrelated to age, although the time since menopause also had some influence. Forearm integral and cortical bone measurements were quite well correlated with TBCa $(r=0.84$ and 0.73 , respectively, $P<0.001$ ). The correlation between spinal bone measurements and any of the forearm measurements, even purely trabecular bone, was weak $(r<0.52, P<0.001)$. Our results show quite clearly that forearm bone measurements cannot be used to predict bone density in the vertebrae. Loss of ovarian function affects bone in general, and trabecular bone in particular. Bone measurements at specific anatomical sites are clearly necessary for studies of metabolic bone diseases and their response to treatment.
\end{abstract}

\section{Introduction}

Quantitative assessment of the skeletal mass has for many years lacked either the precision or the sensitivity to be useful in the study of bone diseases. However, during the past two decades, methods have been developed which have resolved these problems, namely photon absorptiometry $(1,2)$, neutron activation analysis $(3,4)$, and computed tomography $(C T)^{1}(5-8)$. These methods measure either cortical, trabecular, or integral (cortical and trabecular) bone mass at various anatomical sites. Each method has its own advantages and drawbacks. However, the validity of predicting bone mass in one anatomical site from measurements at another, and hence the clinical usefulness of the individual methods, is still controversial. Previous studies comparing regional and total bone mass measurements have largely been conducted in patients with established metabolic bone disease and there are few data from normal populations. Yet such bone mass measurements are very necessary, partic-

Address reprint requests to Dr. Stevenson at his present address: Cavendish Clinic, 21 Wellington Road, London NW8 9SQ, United Kingdom. 1987.

Received for publication 16 June 1986 and in revised form 10 February

1. Abbreviations used in this paper: $\mathrm{BD}$, bone density; $\mathrm{CT}$, computed tomography; TBCa or TBK, total body calcium or potassium.

J. Clin. Invest.

(c) The American Society for Clinical Investigation, Inc. 0021-9738/87/07/0258/05 \$2.00

Volume 80, July $1987,258-262$ ularly in the early postmenopausal period when bone loss is most rapid (9-11). It is at this time when intervention therapy is most effective in preventing postmenopausal osteoporosis (1214). We have therefore performed measurements of bone mass in the appendicular, axial, and whole skeleton during the early postmenopausal period to assess their interrelations.

\section{Methods}

\section{Patients}

The study comprised 70 Caucasian postmenopausal volunteers, mean age $54.3 \mathrm{yr}$ (range 37-65). The majority were within $5 \mathrm{yr}$ of the menopause (mean $52.2 \mathrm{mo}$ ), and measurement of plasma gonadotrophins and gonadal steroid hormones confirmed a true menopausal state in each case. All the women were in apparent good general health, without clinical or radiologic evidence of osteoporosis. None were taking any medication known to influence bone mass or calcium metabolism.

\section{Methods}

For each volunteer, age, height, and weight were recorded. From these parameters, the lean body mass and fat body mass were calculated (15). For 51 women with an intact uterus, time since menopause was also recorded. 63 women underwent all of the following measurements of bone mass, whereas seven underwent two of the three measurements.

\section{Vertebral measurements}

Vertebral trabecular bone density (BD) was measured by whole-body quantitative CT (6). Three 4-mm slices were measured in the vertebral bodies of L2-4, and the mean value was expressed as milligrams per cubic centimeter $\left(\mathrm{mg} / \mathrm{cm}^{3}\right)$ by means of a mineral equivalent phantom. This method has a precision of $2.2 \%$ in vivo, and an accuracy of $2.5 \%$ on phantoms (6). The accuracy error based on measurement of vertebral samples obtained at autopsy has been reported to be $10-25 \%$ (16), although such studies introduce their own inaccuracies.

\section{Forearm measurements}

CT measurements on the radius were made using a specially built (ISOTOM) CT system which incorporated a source of ${ }^{125} \mathrm{I}(29 \mathrm{keV})(8)$. Measurements were made on the dominant wrist at the distal end and midshaft of the radius. These were $\sim 8-10 \%$ and $33 \%$, respectively, of the distance from the ulnar styloid process to the olecranon. The following quantities were measured:

DISTAL RADIUS

Trabecular $B D$. The mean linear attenuation coefficient of the central $50 \%$ of the bone cross section is expressed as $\mathrm{cm}^{-1}(8)$. At this site the measurement includes only trabecular bone.

Integral $B D$. This is the product of the mean linear attenuation coefficient for the complete bone cross section and the cross-sectional area and thus expressed as mass per unit length (cm) (8). At this site, the measurement includes $30 \%$ trabecular and $70 \%$ cortical bone (17), and is highly correlated with BD as determined by single-photon absorptiometry (18).

MIDSHAFT RADIUS

Cortical $B D$. At this site, the measurement includes only cortical bone and is the product of the mean linear attenuation coefficient for the 
Table I. Correlation Coefficients for the Relationship of the Bone Mass Measurements with Age, Time Since Menopause, and Various Physical Parameters

\begin{tabular}{|c|c|c|c|c|c|c|c|}
\hline \multirow[b]{2}{*}{ Measurement } & \multirow[b]{2}{*}{ Age } & \multirow{2}{*}{$\begin{array}{l}\text { Months since } \\
\text { menopause }\end{array}$} & \multirow[b]{2}{*}{ Height } & \multirow[b]{2}{*}{ Weight } & \multirow[b]{2}{*}{ TBK } & \multicolumn{2}{|c|}{ Body mass } \\
\hline & & & & & & Lean & Fat \\
\hline Vertebral BD & $\begin{array}{c}-0.52^{8} \\
(9.3)\end{array}$ & $\begin{array}{l}-0.35^{*} \\
(14.3)\end{array}$ & $\begin{array}{l}-0.05 \\
(26.2)\end{array}$ & $\begin{array}{l}0.03 \\
(23.4)\end{array}$ & $\begin{array}{l}0.14 \\
(27.3)\end{array}$ & $\begin{array}{l}0.12 \\
(31.2)\end{array}$ & $\begin{array}{l}0.00 \\
(62.9)\end{array}$ \\
\hline Forearm trabecular BD & $\begin{array}{l}-0.30^{*} \\
(16.2)\end{array}$ & $\begin{array}{l}-0.42^{\ddagger} \\
(11.2)\end{array}$ & $\begin{array}{r}0.04 \\
(32.3)\end{array}$ & $\begin{array}{l}0.20 \\
(19.3)\end{array}$ & $\begin{array}{l}0.21 \\
(19.0)\end{array}$ & $\begin{array}{l}0.21 \\
(19.0)\end{array}$ & $\begin{array}{l}0.18 \\
(21.6)\end{array}$ \\
\hline Forearm integral BD & $\begin{array}{l}-0.19 \\
(29.4)\end{array}$ & $\begin{array}{l}-0.27 \\
(29.8)\end{array}$ & $\begin{array}{c}0.29^{*} \\
(13.2)\end{array}$ & $\begin{array}{c}0.38^{\ddagger} \\
(7.8)\end{array}$ & $\begin{array}{c}0.41^{\ddagger} \\
(7.2)\end{array}$ & $\begin{array}{r}0.44^{8} \\
(7.3)\end{array}$ & $\begin{array}{l}0.34^{*} \\
(12.3)\end{array}$ \\
\hline Forearm cortical BD & $\begin{array}{l}-0.18 \\
(30.2)\end{array}$ & $\begin{array}{l}-0.27 \\
(31.3)\end{array}$ & $\begin{array}{r}0.27 \\
(21.2)\end{array}$ & $\begin{array}{c}0.45^{8} \\
(5.3)\end{array}$ & $\begin{array}{c}0.42^{8} \\
(6.6)\end{array}$ & $\begin{array}{r}0.48^{8} \\
(8.8)\end{array}$ & $\begin{array}{r}0.42^{8} \\
(7.0)\end{array}$ \\
\hline $\mathrm{TBCa}$ & $\begin{array}{l}-0.16 \\
(22.6)\end{array}$ & $\begin{array}{c}-0.38^{*} \\
(8.6)\end{array}$ & $\begin{array}{c}0.39^{8} \\
(9.2)\end{array}$ & $\begin{array}{r}0.47^{6} \\
(6.9)\end{array}$ & $\begin{array}{l}0.57^{8} \\
(6.0)\end{array}$ & $\begin{array}{r}0.56^{51} \\
(6.1)\end{array}$ & $\begin{array}{c}0.42^{8} \\
(7.8)\end{array}$ \\
\hline
\end{tabular}

Standard errors of estimates are shown in parentheses (SEE \%). ${ }^{*} P<0.05 . \quad{ }^{\ddagger} P<0.01 .{ }^{\S} P<0.001$.

complete bone cross section, expressed as mass per unit length $(\mathrm{cm})(8)$. The precision of these measurements is $\sim 2 \%(8)$.

\section{Total body calcium (TBCa)}

TBCa was determined by neutron activation analysis in vivo (4). The method involves production of whole-body ${ }^{49} \mathrm{Ca}$, by neutrons generated by a cyclotron, which is then measured in a multicrystal whole-body counter. The precision of the measurement is $\sim 3 \%$ with an accuracy of $<8 \%$ (4). The method also allowed measurement of total body potassium (TBK), which is an indicator of skeletal muscle mass.

\section{Statistical analyses}

Single and multiple linear regression analyses were used to examine relationships between the various parameters.

\section{Results}

Vertebral measurements (Table I). The mean vertebral trabecular $\mathrm{BD}( \pm \mathrm{SEM})$ was $131 \pm 4 \mathrm{mg} / \mathrm{cm}^{3}$. BD was negatively correlated with both age (Fig. 1) and months since menopause. There was no significant correlation with height, weight, TBK, lean, or fat body mass.

Forearm measurements (Table I). The mean forearm trabecular BD ( \pm SEM) was $0.70 \pm 0.01 \mathrm{~cm}^{-1}$. There was a negative correlation with age and months since menopause (Fig. 2). No

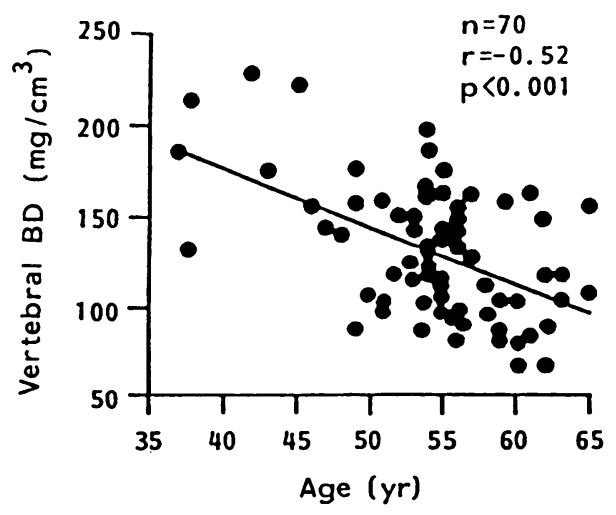

Figure 1. Correlation between vertebral $\mathrm{BD}\left(\mathrm{mg} / \mathrm{cm}^{3}\right)$ and age $(\mathrm{yr})$ in 70 postmenopausal women. significant correlation with height, weight, TBK, lean or fat body mass alone was observed. However, the addition of fat mass brought a substantial improvement to the regression with time since menopause $(r=0.42$ to $r=0.54, P<0.01$ ), whereas the addition of weight brought a small improvement $(P<0.05)$ to the regression with age.

The mean forearm integral BD $( \pm$ SEM) was $3.08 \pm 0.07 \mathrm{~cm}$. There were positive correlations with height, weight, TBK, lean and fat body mass. There was no significant correlation with age or menopause alone, but the addition of time since menopause brought a small improvement $(P<0.05)$ to the regression with weight, lean, and fat body mass.

The mean forearm cortical BD ( \pm SEM) was $2.52 \pm 0.05 \mathrm{~cm}$. This correlated with weight (Fig. 3), TBK, lean (Fig. 4), and fat body mass, but not with age or menopause. However, the addition of time since menopause brought a small improvement $(P<0.05)$ to the regression with fat mass.

$T B C a$ (Table I). The mean TBCa ( \pm SEM) was $767 \pm 11 \mathrm{~g}$. Positive correlations with height, weight, TBK (Fig. 5), lean, and fat body mass were observed, as was a negative correlation with months postmenopause. The addition of time since menopause brought improvements $(P<0.01)$ to the regressions with weight, TBK, and fat mass, with a smaller improvement $(P<0.05)$ to the regression with lean body mass. No significant correlation with age was seen. TBK correlated quite well with the calculated lean body mass $(r=0.74, P<0.001)$.

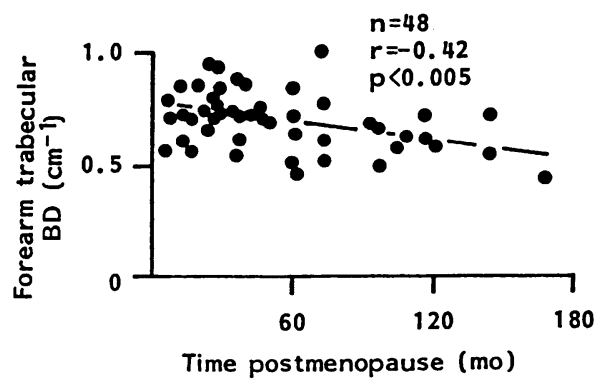

Figure 2. Correlation between forearm trabecular $\mathrm{BD}\left(\mathrm{cm}^{-1}\right)$ and months since menopause in $\mathbf{4 8}$ women. 


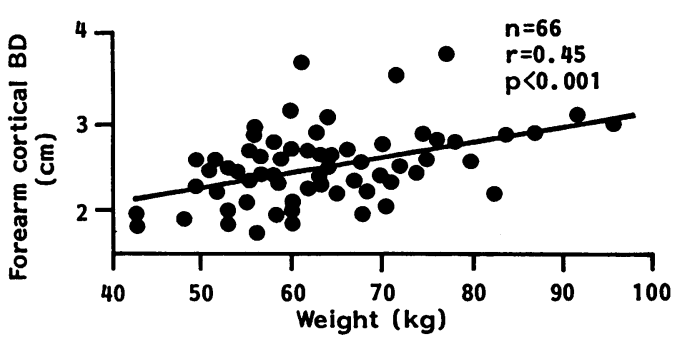

Figure 3. Correlation between forearm cortical BD (cm) and weight $(\mathrm{kg})$ in 66 postmenopausal women.

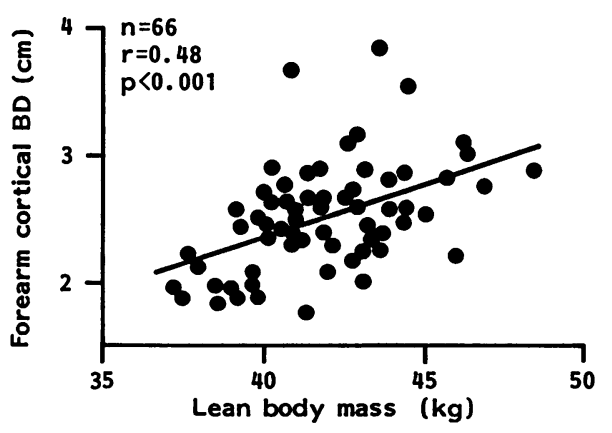

Figure 4. Correlation between forearm cortical BD (cm) and calculated (15) lean body mass $(\mathrm{kg})$ in 66 postmenopausal women.

Interrelations of measurements (Table II). There were fairly close correlations between TBCa and either forearm integral (Fig. 6) or cortical BD. Indeed, these peripheral CT measurements gave a better estimate of TBCa than that reported for singlephoton absorptiometry measurements (19). However, correlations between TBCa and either vertebral BD or forearm trabecular BD were weaker. The correlations between vertebral trabecular $\mathrm{BD}$ and all of the forearm measurements were similarly weak (Fig. 7). Contrary to previous observations (20), no significant improvement in any correlation was observed when forearm measurements were adjusted for height.

\section{Discussion}

Our results clearly demonstrate that measurements of TBCa or any of BD performed in the forearm are not highly correlated with vertebral trabecular $\mathrm{BD}$, which therefore cannot be predicted with a degree of certainty comparable to direct measure-

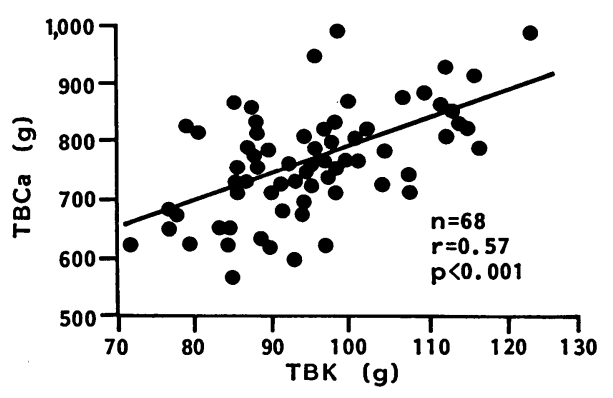

Figure 5. Correlation between TBCa (g) and TBK (g) in 68 postmenopausal women.
Table II. Correlation Coefficients for the Interrelations of the Various Bone Mass Measurements

\begin{tabular}{lclll}
\hline & BD & & & \\
\cline { 2 - 5 } Measurement & Vertebral & $\begin{array}{l}\text { Forearm } \\
\text { trabecular }\end{array}$ & $\begin{array}{l}\text { Forearm } \\
\text { integral }\end{array}$ & $\begin{array}{l}\text { Forearm } \\
\text { cortical }\end{array}$ \\
\hline Forearm trabecular BD & $0.52^{*}$ & - & - & - \\
& $(11.3)$ & - & - & - \\
Forearm integral BD & $0.51^{*}$ & $0.72^{*}$ & - & - \\
& $(9.6)$ & $(5.3)$ & - & - \\
Forearm cortical BD & $0.40^{*}$ & $0.55^{*}$ & $0.70^{*}$ & - \\
& $(14.2)$ & $(12.6)$ & $(9.3)$ & - \\
TBCa & $0.54^{*}$ & $0.64^{*}$ & $0.84^{*}$ & $0.73^{*}$ \\
& $(10.2)$ & $(10.4)$ & $(6.3)$ & $(10.6)$ \\
\hline
\end{tabular}

Standard errors of estimates are shown in parentheses (SEE \%). $* P<0.001$.

ment. This is of considerable practical importance because postmenopausal osteoporosis occurs most frequently in the vertebral bodies (21). Studies using forearm bone measurements have proven of value in comparing the efficacy of various forms of treatment for preventing postmenopausal bone loss $(22,23)$. However, such studies have involved very large numbers of patients. Our findings strongly suggest that, in the assessment of individual patients, specific axial bone measurements are essential. Other studies using a variety of methods for bone measurements have found weak correlations between forearm integral BD and spine of an order similar to ours (20, 24-26).

It is of interest that one factor that influences all the bone measurements is time since menopause, emphasizing the importance of loss of ovarian function on the skeleton (27). TBCa, which reflects $80 \%$ cortical and $20 \%$ trabecular bone (28), forearm integral bone, which reflects $70 \%$ cortical and $30 \%$ trabecular bone (17), and forearm cortical bone are measurements of mass, and thus are related to physical characteristics-height, weight, and skeletal muscle mass-as previously shown (29). These measurements are not significantly related to age, but there is clearly some influence from the menopause. However, vertebral and forearm trabecular BD are influenced by both age and time since menopause, although not by the physical parameters. It is perhaps a little surprising that the trabecular component of the forearm BD is only weakly correlated to that of the spine (20, 24-26). However, studies of patients with various metabolic bone

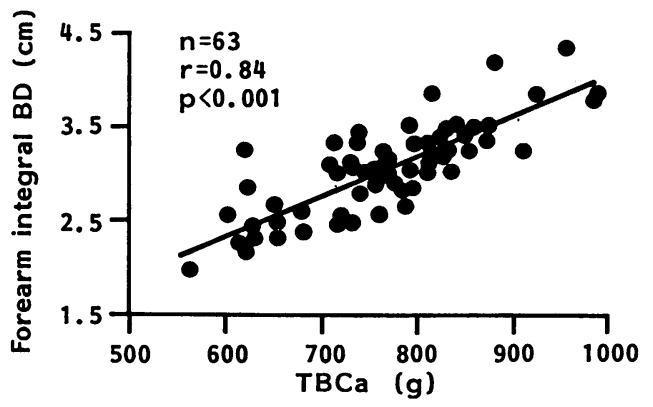

Figure 6. Correlation between forearm integral $\mathrm{BD}(\mathrm{cm})$ and TBCa $(\mathrm{g})$ in 63 postmenopausal women. 


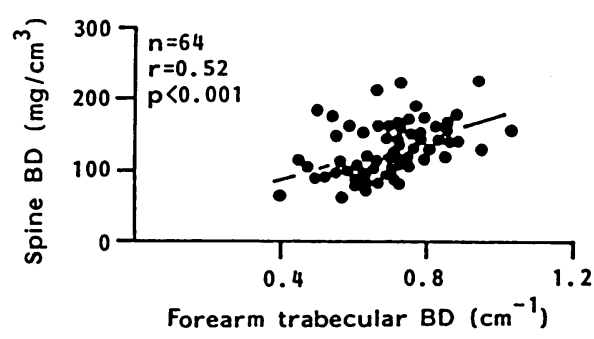

Figure 7. Correlation between vertebral $\mathrm{BD}\left(\mathrm{mg} / \mathrm{cm}^{3}\right)$ and forearm trabecular $\mathrm{BD}\left(\mathrm{cm}^{-1}\right)$ in 64 postmenopausal women.

diseases have suggested that appendicular trabecular bone is relatively inactive compared with that in the axial skeleton (3033). By far the most important metabolic bone disease is postmenopausal osteoporosis in terms of frequency, morbidity, mortality, and cost (27). No single bone measurement has been able to separate totally an osteoporotic population from age and sex-matched normals when the definition of osteoporosis was the presence of fracture (34-37). However, if such a definition is used, it is hardly surprising that there is considerable overlap between patients and controls. A considerable proportion of postmenopausal controls would have a bone mass as low as the so-called osteoporotics, and indeed, could convert to the osteoporotic classification instantaneously with one episode of minor trauma causing fracture. The treatment of the established osteoporotic remains so far unrewarding in terms of adequately restoring bone mass, yet prevention of the disease in its early stages is certainly possible (12-14). Hence suitable measurements of bone mass in the early postmenopausal period are paramount. Our study emphasizes the necessity for measurements of the axial skeleton at this time; appendicular measurements of any type alone are clearly inadequate in determining the skeletal status of individual patients.

\section{Acknowledgments}

We thank Professor Michael Healy and Dr. Nigel Shennan for advice on statistical analyses and data presentation.

These studies were supported in part by Laboratoires Besins-Iscovesco, Paris and Ciba-Geigy, Basel. The whole-body CT scanner was donated by the Bernard Sunley Trust.

\section{References}

1. Cameron, J. R., R. B. Mazess, and J. A. Sorenson, 1968. Precision and accuracy of bone mineral determination by direct photon absorptiometry. Invest. Radiol. 3:141-150.

2. Madsen, M., W. Peppler, and R. B. Mazess. 1976. Vertebral and total body bone mineral content by dual photon absorptiometry. In Proceedings of 11 th European Symposium on Calcified Tissues, 1975. S. Pors-Nielsen and E. Hjorting-Hansen, editors. FADL Publishing, Copenhagen. 316-364.

3. Chamberlain, M. J., J. H. Fremlin, D. K. Peters, and H. Philip. 1968. Total body calcium by whole body neutron activation analysis: a new technique for study of bone disease. Br. Med. J. ii:581-583.

4. Spinks, T. J. 1979. Effect of size and composition of the body on absolute measurements of calcium 'in vivo'. Phys. Med. Biol. 24:976987.

5. Cann, C. E., and H. K. Genant. 1980. Precise measurement of vertebral mineral content using computed tomography. J. Comput. Assist. Tomogr. 4:493-500.
6. Banks, L. M., and J. C. Stevenson. 1986. Modified method of spinal computed tomography for trabecular bone mineral measurement. J. Comput. Assist. Tomogr. 10:463-467.

7. Genant, H. K., and D. P. Boyd. 1977. Quantitative bone mineral analysis using dual-energy computed tomography. Invest. Radiol. 12: 545-551.

8. Exner, G. U., A. Prader, U. Elsasser, P. Ruegsegger, and M. Anliker. 1979. Bone densitometry using computed tomography. 1. Selective determination of trabecular bone density and other bone mineral parameters: normal values in children and adults. Br. J. Radiol. 52:14-23.

9. Krolner, B., and S. P. Nielsen. 1982. Bone mineral content of the lumbar spine in normal and osteoporotic women: cross-sectional and longitudinal studies. Clin. Sci. 62:329-336.

10. Genant, H. K., C. E. Cann, B. Ettinger, and G. S. Gordan. 1982. Quantitative computed tomography of vertebral spongiosa: a sensitive method for detecting early bone loss after oophorectomy. Ann. Intern. Med. 97:699-705.

11. Abdallah, H., D. M. Hart, and R. Lindsay. 1984. Differential bone loss and effects of long-term oestrogen therapy after oophorectomy. In Osteoporosis. C. Christiansen, C. D. Arnaud, B. E. C. Nordin, A. M. Parfitt, W. A. Peck, and B. L. Riggs, editors. Glostrup Hospital, Glostrup, Denmark. 621-623.

12. Nachtigall, L. E., R. H. Nachtigall, R. D. Nachtigall, and E. M. Beckman. 1979. Estrogen replacement therapy: a 10-year prospective study in relationship to osteoporosis. Obstet. Gynaecol. 53:277-281.

13. Lindsay, R., D. M. Hart, C. Forrest, and C. Baird. 1980. Prevention of spinal osteoporosis in oophorectomised women. Lancet. ii: 151-154.

14. Christiansen, C., M. S. Christensen, and I. Transbol. 1981. Bone mass in postmenopausal women after withdrawal of oestrogen/gestagen replacement therapy. Lancet. i:459-461.

15. Boddy, K., P. C. King, R. Hume, and E. Weyers. 1972. The relationship of total body potassium to height, weight and age in normal adults. J. Clin. Pathol. 25:512-517.

16. Laval-Jeantet, A. M., B. Roger, S. Bouysse, C. Bergot, and R. B. Mazess. 1986. Influence of vertebral fat content on quantitative CT density. Radiology. 159:463-466.

17. Schlenker, R. A., and W. W. VonSeggen. 1976. The distribution of cortical and trabecular bone mass along the lengths of the radius and ulna and the implications for in vivo bone mass measurements. Calcif. Tissue Res. 20:41-52.

18. Elsasser, W., and J. Reeve. 1980. Bone density measurement with computed tomography. Br. Med. Bull. 36:293-296.

19. Horsman, A., L. Burkinshaw, D. Pearson, C. B. Oxby, and R. M. Milner. 1983. Estimating total body calcium from peripheral bone measurements. Calcif. Tissue Int. 35:135-144.

20. Hesp, R., G. M. Bydder, U. Elsasser, J. Reeve, and T. J. Spinks. 1982. Regional bone density measurements compared to total body calcium in osteoporosis. Metab. Bone Dis. Relat. Res. 4:169-173.

21. Marshall, D. H., A. Horsman, M. Simpson, R. M. Francis, and M. Peacock. 1984. Fractures in elderly women: prevalence of wrist, spine and femur fractures and their concurrence. In Osteoporosis. C. Christiansen, C. D. Arnaud, B. E. C. Nordin, A. M. Parfitt, W. A. Peck, and B. L. Riggs, editors. Glostrup Hospital, Glostrup, Denmark. 361-363.

22. Christiansen, C., M. S. Christensen, P. McNair, C. Hagen, E. Stockland, and I. Transbol. 1980. Prevention of early postmenopausal bone loss: controlled 2-year study in 315 normal females. Eur. J. Clin. Invest. 10:273-279.

23. Christiansen, C., M. S. Christensen, P. Rodbro, C. Hagen, and I. Transbol. 1981. Effect of 1,25-dihydroxyvitamin $D$ in itself or combined with hormone treatment in preventing post-menopausal osteoporosis. Eur. J. Clin. Invest. 11:305-309.

24. Hangartner, T. N., T. R. Overton, and W. M. Regal. 1983. Comparison of trabecular bone density of axial and peripheral sites using computed tomography. In Clinical Disorders of Bone and Mineral Metabolism. B. Frame and J. T. Potts, Jr., editors. Excerpta Medica, Amsterdam. 54-57.

25. Richardson, M. L., H. K. Genant, C. E. Cann, B. Ettinger, 
G. S. Gordan, F. O. Kolb, and U. J. Reiser. 1985. Assessment of metabolic bone diseases by quantitative computed tomography. Clin. Orthop. Rel. Res. 195:224-238.

26. Harma, M., P. Karjalainen, V. Hoikka, and E. Alhava. 1985. Bone density in women with spinal and hip fractures. Acta Orthop. Scand. 56:380-385.

27. Stevenson, J. C., and M. I. Whitehead. 1982. Postmenopausal osteoporosis. Br. Med. J. 285:585-588.

28. International Commission on Radiological Protection. 1975. No. 23. Report of the Task Group on Reference Man. Pergamon Press Ltd., Oxford. 66.

29. Nilas, L., A. Gotfredsen, and C. Christiansen. 1986. Total and local bone mass before and after normalization for indices of bone and body size. Scand. J. Clin. Lab. Invest. 46:53-57.

30. Krolner, B., S. Pors Nielsen, B. J. Lund, L. H. Sorensen, and A. Uhrenholdt. 1980. Measurement of bone mineral content (BMC) of the lumbar spine. II. Correlation between forearm BMC and lumbar spine BMC. Scand. J. Clin. Lab. Invest. 40:665-670.

31. Riggs, B. L., H. W. Wahner, W. L. Dunn, R. B. Mazess, K. P. Offord, and L. J. Melton III. 1981. Differential changes in bone mineral density of the appendicular and axial skeleton with aging. J. Clin. Invest. 67:328-335.
32. Seeman, E., H. W. Wahner, K. P. Offord, R. Kumar, W. J. Johnson, and B. L. Riggs. 1982. Differential effects of endocrine dysfunction on the axial and the appendicular skeleton. J. Clin. Invest. 69:13021309.

33. Genant, H. K., G. S. Gordan, and P. G. Hoffman. 1983. Osteoporosis. 1. Advanced radiologic assssment using quantitative computed tomography: Medical Staff Conference, University of California, San Francisco. West. J. Med. 139:75-84.

34. Goldsmith, N. F., J. O. Johnson, H. Ury, G. Vose, and C. Colbert. 1971. Bone-mineral estimation in normal and osteoporotic women. $J$. Bone Jt. Surg. Am. Vol. 53A:83-100.

35. Kruse, H. P., F. Kuhlencordt, and J.-D. Ringe. 1976. Correlation of clinical, densitometric and histomorphometric data in osteoporosis. In Proceedings of 11 th European Symposium on Calcified Tissues, 1975. S. Pors Nielsen and E. Hjorting-Hansen, editors. FADL Publishing, Copenhagen. 457-461.

36. Mazess, R. B., W. W. Peppler, R. W. Chesney, T. A. Lange, W. Lindgren, and E. Smith. 1984. Does bone measurement on the radius indicate skeletal status? J. Nucl. Med. 25:281-288.

37. Yano, K., R. D. Wasnich, J. M. Vogel, and L. K. Heilbrun. 1984. Bone mineral measurements among middle-aged and elderly Japanese residents in Hawaii. Am. J. Epidemiol. 119:751-764. 